\title{
Master World Records show minor gender differences of performance decline with aging
}

\author{
Paolo Gava (1), Barbara Ravara $(1,2)$
}

(1) A\&C M-C Foundation for Translational Myology, Padova, Italy; (2) Interdepartmental Research Center of Myology, Department of Biomedical Science, University of Padova, Italy

This article is distributed under the terms of the Creative Commons Attribution Noncommercial License (CC BY-NC 4.0) which permits any noncommercial use, distribution, and reproduction in any medium, provided the original author(s) and source are credited.

\begin{abstract}
Aging behaviours are significantly different in females and males, e.g., the former have a longer life expectancy, but consistently a weaker muscle force. Our purpose is to analyse possible gender-differential declines of skeletal muscle performance. The method to find out the decline of performances with aging is based on a parametric analysis of the World Records of Master athletes in different Track and Field events. The analysis is a transformation (normalization) of sports results into dimensionless parameters ranging from the maximum value of 1 (for the absolute world record) to decreasing values with decreasing performances. Master athletes compete in age groups of 5 years till the age of 100 years, thus their World Records are lists of up to 16 data. Results of the normalization procedure are trend-lines indicating that the decline starts not later than the age of thirty years for both women and women. The decline with aging of the muscle performances indicates only minor gender differences in the aging process and all trend-lines tend to zero at about the age of 110 years. The approach, making use of a homogeneous cohort of testers, gets rid of the main confounding factors biasing other kind of studies of the muscle performance decline with aging, in particular clinical studies. Comparing normalized female and male World Records of Master athletes, a surprise emerged: aging decline is very similar, if not identical, the unique exception to the general rule of gender differences in sports activities. The substantial identity of decline trends among females and males suggests that neuro-hormonal differences among genders poorly influence the aging decline, being conceivably related to fundamental cell bioregulators, such as those of cellular energy metabolism and/or their epigenetic regulatory mechanisms.
\end{abstract}

Key Words: Masters World Records, aging performance decay, gender differences.

Eur J Transl Myol 29 (3): 218-226, 2019

Aging behaviours are significantly different in females and males, the former group having a longer life expectancy, ${ }^{1}$ though having consistently weaker muscle strength. ${ }^{2-4}$ The main purpose of the present study is to establish if this is true also for the decline of performance of aging females in comparison to males. Gava et al. ${ }^{5}$ reported some interesting conclusions analysing the decline of the World Records of male Master athletes in Track and Field competitions, in particular in running, jumping and throwing athletic events, in general agreement with previous studies. ${ }^{6-13}$ Master Athletes are athletes competing within age groups divided into categories of five-year periods, from 35 - 39, $40-44$, and so on, until the age of 110 years. This study compared the declining trends of the male Master athletic World Records, but after transformation of the measured athletic performance into a parameter proportional to the power developed by the athlete in carrying out the athletic gesture. Such parameter is a dimensionless number ranging from the maximum value of 1 (for the absolute world record) to decreasing values with decreasing performance. The results of this normalization are rows of up to 16 performance parameters conveniently interpolated with polynomial trend-lines that directly compare performances of very different athletic gestures. This approach, making use of a very homogeneous cohort of testers, gets rid of the main confounding factors in other studies of age-related performance decay, as different length of clinical longitudinal studies, ${ }^{11,14-16}$ or different modalities to measure strength, power and resistance to fatigue in aging. ${ }^{17}$ Main conclusion is that the consistent decreased values of all female Master records almost disappear after normalization suggesting that the overall mean of performance decay is, together 
with longevity, a fundamental biological carachteristic of the modern Homo Sapiens, related to fundamental cell bioregulators, such as those of cellular energy metabolism and/or of their epigenetic regulatory mechanisms.

\section{Materials and Methods}

\section{World Records database}

The method required, first, the creation of a database with all the World Records of the main disciplines of athletics: 11 track, 4 throwing and 4 jumping events. ${ }^{5}$ The same Records must also be collected for all categories of the Master Athletes, both females and males (14 categories each). The data collected in this study come from the official archives of the world athletic associations: IAAF, International Association of Athletics Federation (http://www.iaaf.org/) ${ }^{18}$ [for absolute World Records of Senior Athletes], and the World Master Athletics (http://www.world-masters-athletics.org/) ${ }^{19}$ for the World Records of Master Athletes. The database contains about 280 World Records, each associated with the contour data (discipline, performance, athlete's name, athlete's age, athlete's nationality, date of performance, location of the performance). All data used in this study are public data collected in events officially recognized by the relative federation of athletics. The data of this paper are the official data valid in May 2013, for both female and male Master athletes. See discussion. The athletics performances are defined by a very strict protocol valid all over the world and controlled by judges who, besides extensive experience, are all athletic fans and very rigorous in carrying out their duties. These observations on data quality are made to highlight the enormous qualitative difference between these data and many of the clinical data on the topic, collected with much simpler procedures and detected with variable care by general paramedical staff and technical means, very different from the measuring instruments used in international athletic competitions. ${ }^{5}$ All the athletic performances are "power" performances: for instance the work to displace the body of the athlete from the start to the finishing line divided by the time spent is directly proportional to the power developed (the less the time, the more the power); the distance reached by the piece of equipment in throwing is directly proportional to the kinetic energy transmitted to the equipment by the athletic action, i.e. again proportional to the physical power developed by the athlete.

\section{Normalization procedure}

\section{One-step normalizations}

The Master World Records were then "normalized" with respect to each relevant absolute world record. The normalization of the Records increasing with age (such as the time for the running events) is obtained by dividing the absolute Record by the Master Record while the normalized value of the Records decreasing with age (such as the height for the high jumping events and the distance for the throwing events and the long jumping events) is calculated in the opposite way: the Master Record divided per the absolute Record. Consequently the normalized Records of each event are a set of dimensionless values that decrease with age, from 1 (absolute Record normalized value) to 0 for a null value. With such procedure the performances always decrease with age, in line with the usual idea of decline, regardless of the fact that the measured values of the performances increase (running) or decrease (throwing, jumping) with age. This is to allow for a form of measurement across different events that reflects the fact that increased age is generally associated with a decrease in performance, and comparison across events follows the same trend in metric change.

\section{Two-step normalizations}

The vertical jumping performances need a two-step normalization process in order to obtain the normalized dimensionless parameter proportional to the power developed in the performance. Actually the power developed by the athletes is associated to the displacement of the Center of Mass (CoM) of their own body, which is essentially equal to the jumping length for the horizontal jumping (Long Jump and Triple Jump) but it is not proportional to the height of the cross bar in the vertical jumping (High Jump and Pole Vault). The height of the vertical jumps is unquestionably and mainly linked to the speed of the athlete's CoM at the time of detachment. Such speed, according to Newton's second law of motion, depends directly on the impulse imparted to the athlete's mass at take-off. The impulse in turn depends on the athlete's ability to accelerate his CoM, a capacity that is directly linked to the power developed in the athletic gesture. For this reason the lifting of the athlete's center of gravity in the jump is directly connected to the power developed by the athlete in the execution of the jump; ${ }^{20,21}$ in spite of the controversial objections raised by some authors. ${ }^{22,23}$ In performing the vertical jumps the athlete has to raise his own CoM from a starting level at about $110-120 \mathrm{~cm}$ from ground at the take-off point to $10-20 \mathrm{~cm}$ above the cross bar. In other words, the athlete has to develop enough power to raise his own center of gravity the jump height minus 1 meter. This assumption is somewhat coarse even though conceptually correct. The CoM can pass (theoretically) also under the bar in the jumps performed with the best Fosbury technique and passes well over $20 \mathrm{~cm}$ above the bar in jumps performed with less effective techniques, especially with older athletes. Anyhow, this adjustment does not take into account the horizontal displacement of the CoM from his initial position in front of the cross bar at take-off to his final position beyond the cross bar at landing. Despite these approximations, the method allows a conceptually correct "normalization" of vertical jumps. The performance of Throwing events are also further normalized by taking into account the decreasing weight of the implements with the increasing age of the 
Table 1. Senior and Master World Record Performance: $100 \mathrm{~m}$ run and Long Jump of male and female athletes

\begin{tabular}{|c|c|c|c|c|}
\hline Event & $\begin{array}{c}100 \mathrm{~m} \\
\text { male }\end{array}$ & $\begin{array}{c}\text { Long Jump } \\
\text { male }\end{array}$ & $\begin{array}{c}100 \mathrm{~m} \\
\text { female }\end{array}$ & $\begin{array}{c}\text { Long Jump } \\
\text { female }\end{array}$ \\
\hline $\begin{array}{c}\text { World } \\
\text { Record }\end{array}$ & 9.58 & 8.95 & 10.49 & 7.52 \\
\hline Master 35 & 9.97 & 8.50 & 10.74 & 6.99 \\
\hline Master 40 & 10.29 & 7.68 & 11.09 & 6.55 \\
\hline Master 45 & 10.72 & 7.77 & 11.34 & 5.62 \\
\hline Master 50 & 10.88 & 6.84 & 11.67 & 5.41 \\
\hline Master 55 & 11.44 & 6.35 & 13.3 & 5.01 \\
\hline Master 60 & 11.7 & 6.07 & 13.75 & 4.75 \\
\hline Master 65 & 12.37 & 5.47 & 14.1 & 4.64 \\
\hline Master 70 & 12.77 & 5.19 & 14.76 & 4.26 \\
\hline Master 75 & 13.49 & 4.83 & 15.91 & 3.77 \\
\hline Master 80 & 14.35 & 4.36 & 18.42 & 3.05 \\
\hline Master 85 & 16.16 & 3.77 & 19.83 & 2.54 \\
\hline Master 90 & 17.53 & 3.26 & 23.18 & 1.77 \\
\hline Master 95 & 20.41 & 2.14 & 15.48 & \\
\hline Master 100 & 29.83 & & & \\
\hline
\end{tabular}

Master athletes. The distance reached by any throwing implement is inversely proportional to the equipment weight, with the assumption that the kinetic energy transferred to the equipment by the athlete is the same, without considering the second-order parameters such as aerodynamic resistance. This second normalization step overcomes the problem of comparing performances of throwing events at different age groups. The Master World Records are normalized with respect to the absolute World Record and with respect to the equipment weight. The final results of the normalization procedure, i.e. the dimensionless power parameter for each athletic event and for all the age groups and genders (see figures below). An example of the normalization procedure for the $100 \mathrm{~m}$ run and for the long jump (men above and women below) is given in Tables 1 and 2 .

\section{Results}

A selection of dimensionless parameter for 6 selected athletic events (2 running disciplines, 2 jumping disciplines and 2 throwing disciplines) calculated with our normalization procedure is presented in Figure 1 for men and in Figure 2 for women. In these diagrams the average linear interpolation (black dotted line) is also indicated. It is easy to see that the general trend of decline is very similar for females and for males and that the linear interpolation is almost identical. For all the events the declining trend-lines start very close to the age of 30 and point to zero at the age of 110 years. These two
Table 2. Senior and Master World Record after normalization procedure: 100 m run and Long Jump of male and female athletes

\begin{tabular}{|c|c|c|c|c|}
\hline Event & $\begin{array}{c}100 \mathrm{~m} \\
\text { male }\end{array}$ & $\begin{array}{c}\text { Long Jump } \\
\text { male }\end{array}$ & $\begin{array}{c}100 \mathrm{~m} \\
\text { female }\end{array}$ & $\begin{array}{c}\text { Long Jump } \\
\text { female }\end{array}$ \\
\hline $\begin{array}{c}\text { World } \\
\text { Record }\end{array}$ & 1.000 & 1.000 & 1.000 & 1.000 \\
\hline Master 35 & 0.950 & 0.950 & 0.977 & 0.930 \\
\hline Master 40 & 0.950 & 0.858 & 0.946 & 0.871 \\
\hline Master 45 & 0.858 & 0.812 & 0.925 & 0.747 \\
\hline Master 50 & 0.812 & 0.764 & 0.899 & 0.719 \\
\hline Master 55 & 0.764 & 0.709 & 0.789 & 0.666 \\
\hline Master 60 & 0.709 & 0.678 & 0.763 & 0.632 \\
\hline Master 65 & 0.678 & 0.611 & 0.744 & 0.617 \\
\hline Master 70 & 0.611 & 0.580 & 0.711 & 0.566 \\
\hline Master 75 & 0.580 & 0.540 & 0.659 & 0.501 \\
\hline Master 80 & 0.540 & 0.487 & 0.569 & 0.406 \\
\hline Master 85 & 0.487 & 0.421 & 0.529 & 0.338 \\
\hline Master 90 & 0.421 & 0.364 & 0.453 & 0.235 \\
\hline Master 95 & 0.364 & 0.239 & 0.296 & \\
\hline Master 100 & 0.239 & & & \\
\hline
\end{tabular}

diagrams have the sole purpose of providing an overview of the normalization procedure with the athletic World Records of Senior and Master athletes. For the scope of our study it is perhaps of greater interest the direct comparison of the female (red) and male (blue) dimensionless parameters in the three categories of athletics, that is in all the running, jumping and throwing events. Figure 3 presents the comparison of all the 11 running events considered in this study for females (red lines) and males (blue lines). The decline of all the disciplines is very similar and it is very gentle from 30 to 50 years, it is almost linear from 50 to 70 years and then the decay is progressively steeper. Men and women are almost overlapping till the age of 50 years, then women are declining a bit more than men. In the throwing events (Figure 4) women (red lines) are declining quicker than men (blue lines) from 30 to 60 years, then the decline parameter of women and men are almost overlapping. Finally in the jumping events (Figure 5) the decline lines are mixed and no real difference between female and male can be recognised as general trend. The comparison of the overall decline of women and men in these three diagrams shows that the performances, where explosive power is involved (jumping and throwing events), decline with age faster than the running performances (lasting at least 10 second or more) for both women and men. Therefore, there are no clear differences between gender in terms of decline across the events; with both women and men following a close trend. 


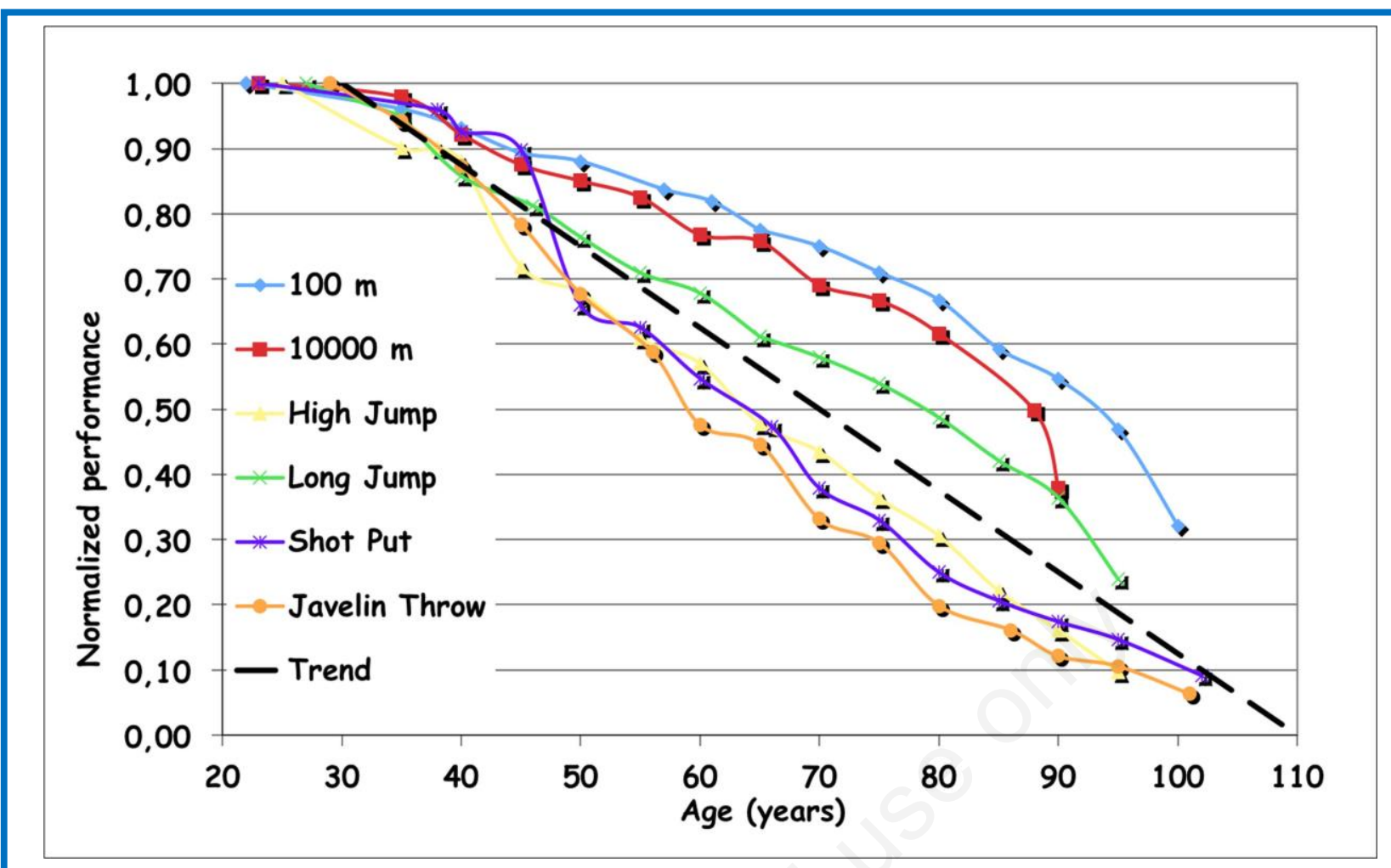

Fig 1. Trend-lines of normalized parameters. Overview of results of normalization procedure for male athletic World Records of Senior and Master Athletes.

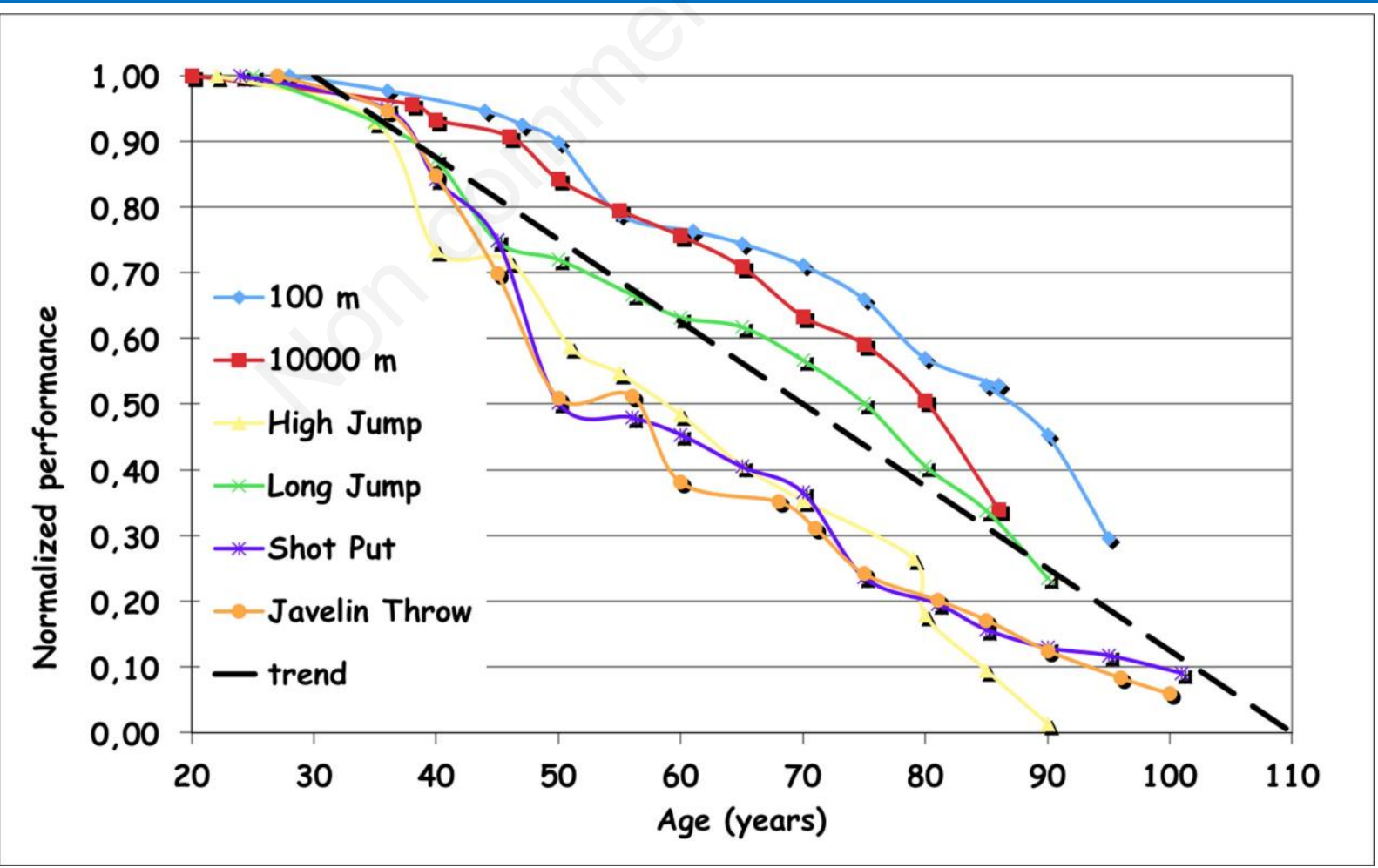

Fig 2. Trend-lines of normalized parameters. Overview of results of normalization procedure for female athletic World Records of Senior and Master Athletes. 


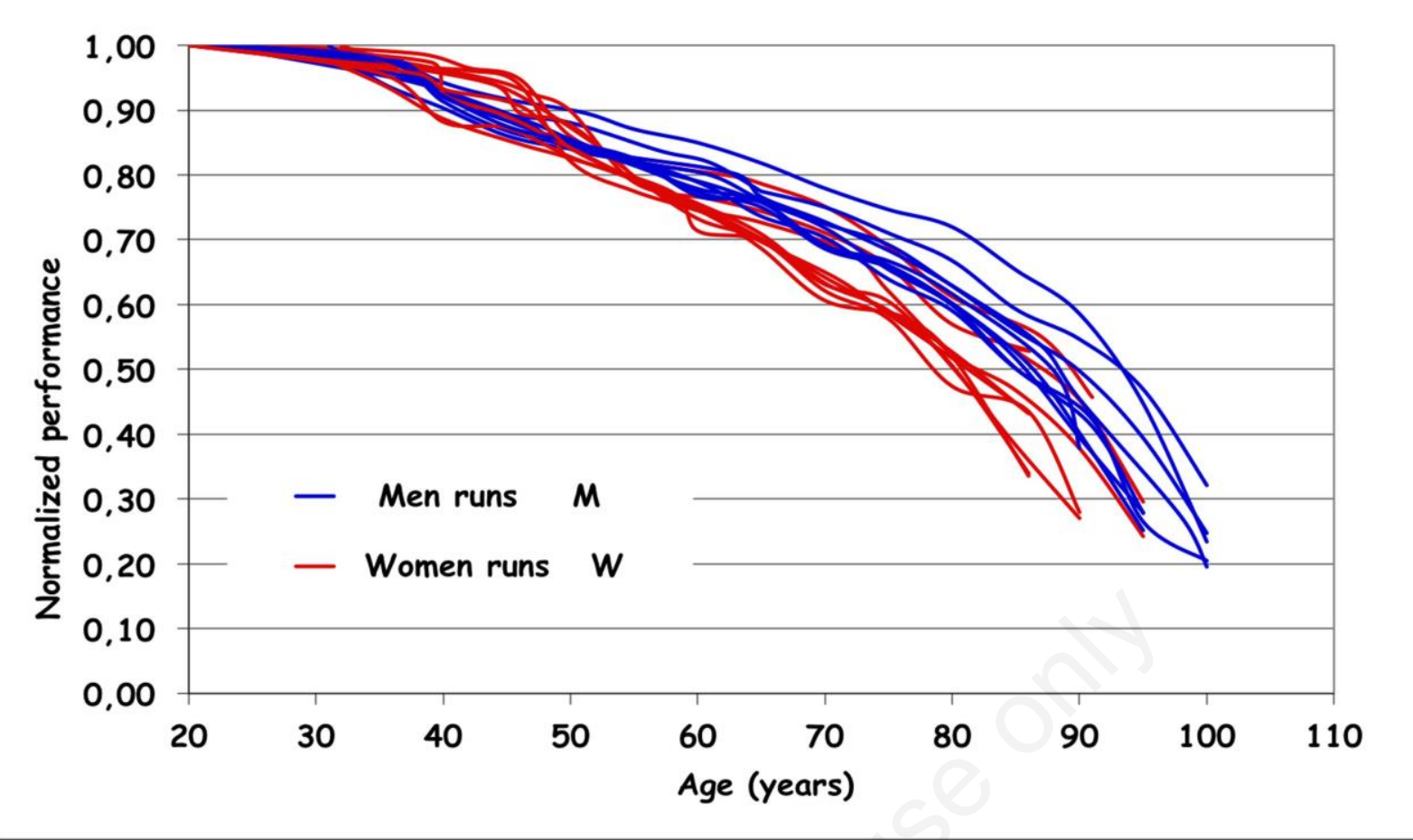

Fig 3. Comparison of normalized running parameters of male and female Masters Athletes. Decline of running disciplines is very similar. It is very gentle from 30 to 50 years, it is almost linear from 50 to 70 years and then the decay is progressively steeper.

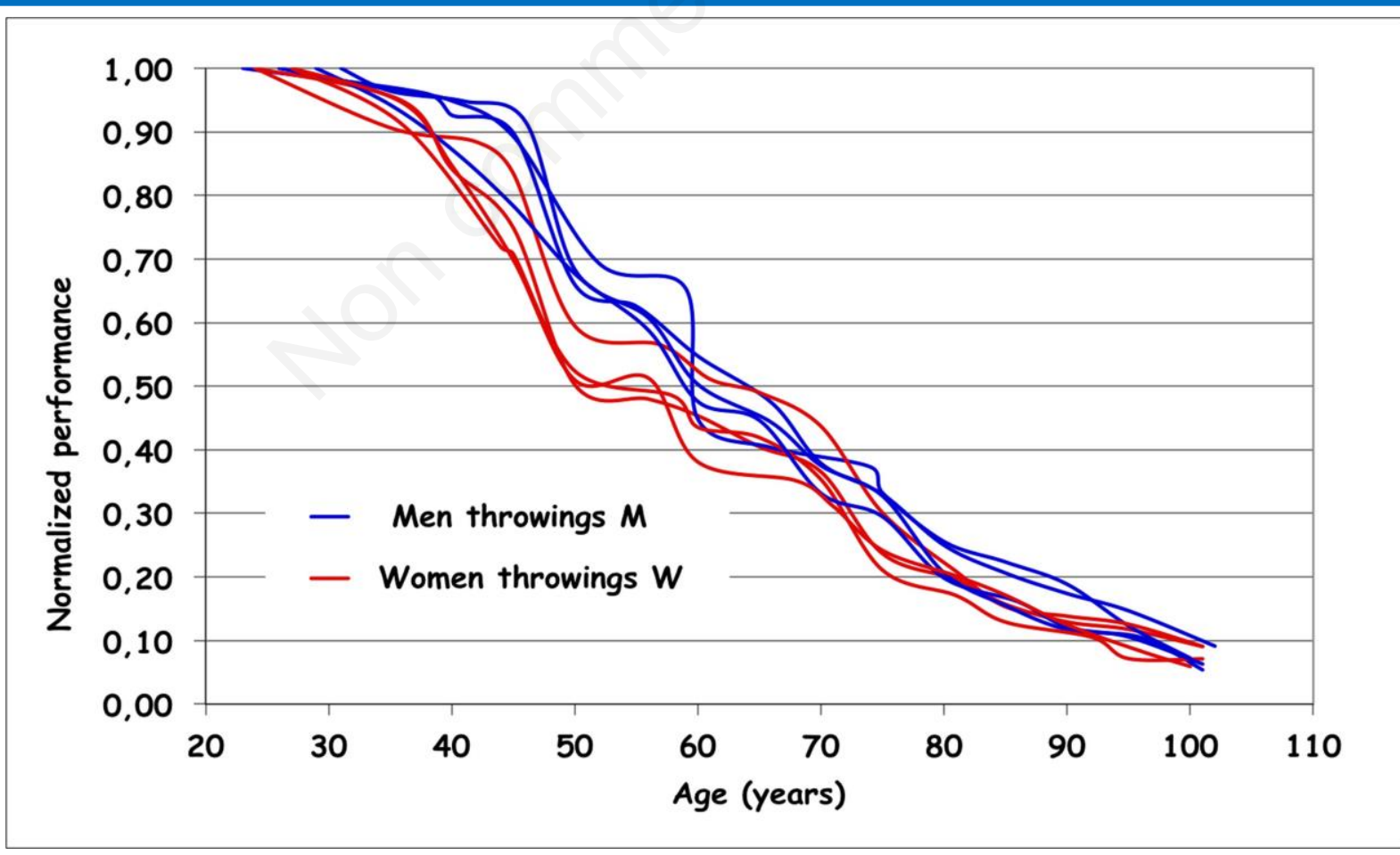

Fig 4. Comparison of normalized throwing parameters. In the throwing events women (red lines) are declining quicker than men (blue lines) from 30 to 60 years, then the parameters of men and women overlap. 


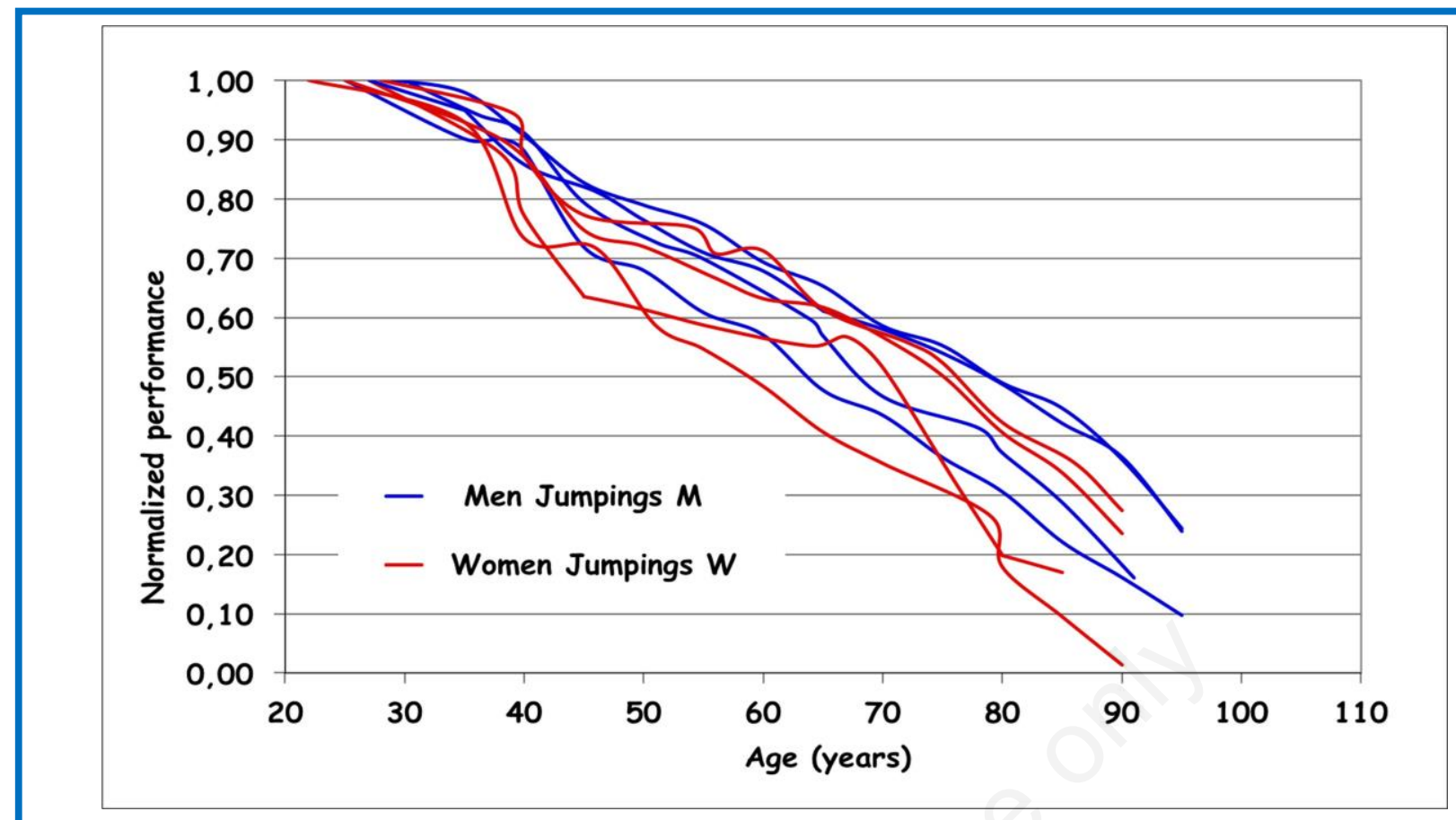

Fig 5. Comparison of normalized jumping parameters. In the jumping events the decline lines are mixed and no real difference between male and female can be recognized.

\section{Discussion}

World Record holders are excellent athletes and out of the ordinary people: their performances are far better from the performances of any other person. They are the "perfect" specimens of the human being: all of them are perfectly healthy, perfectly trained, perfectly fit for the purpose (their discipline) and $100 \%$ motivated to draw the maximum possible performance from their body. Consequently, they are "perfect" testers for each track and field event, in the sense that the World Record holders are a very homogeneous cohort. The performance of these testers cannot be used to evaluate the performance of any ordinary person but, in our procedure, we "normalize" all World Records by making the relationship between two World Records, the Absolute Record (i.e., of Senior Athletes) and the Master Record. This procedure eliminates the "special" part of the World Records because the peculiarity of the different Track and Field events is both numerator and denominator, eliminating each other as in every division. Consequently, our dimensionless parameter is not referred to a "peculiar" specimen of human being but to the "normal" human being. The term "normalization procedure" cannot be more appropriate. The declining trends of the dimensionless parameter of this study are the decline of the "normal" aging people, that is, persons without any genetic handicap or disabling pathology. Analysis of Paralympic Master Athletes performances could be an interesting extension of our study, though we suspect that the study will be biased by the eventual differential worsening of the underlinying handicaps/pathologies. Each of us will thus decline the same way even if, unfortunately, we are prone to some invalidating pathology with aging. This may also happen to Master Athletes, in later life, after obtaining their World Record.

The results of this kind of analysis about the aging decline in physical performance of skeletal muscle reveal some indisputable elements:

- Despite the differences in absolute performance of female and male skeletal muscles (from 10 to $15 \%$ lower in females $)^{2-4}$ decline in trend with age is very similar.

- The decline of performances in the activities that mainly involve the lower limbs for a non-explosive activity but protracted in time (i.e. all the running events) begins very gently in both females and males. In this type of physical activity (deambulation) the human body decays to $50 \%$ of youth performance at an age between 80 and 90 years, a fact that is not part of the common consensus (Figure 3). It is worth noting that Lepers R, Stapley PJ. (2016) ${ }^{24}$ studying gender differences in the limits of human endurance observed that "The relative stability of gender differences observed across the ages suggests that the age-related declines in physiological function did not differ between males and females".

- The performance decline in the jumping events (explosive activities that essentially involve the lower limbs) falls almost linearly with age, both in females 
and males, and falls to $50 \%$ of youth value between 60 and 80 years of age (Figure 5). The dimensionless parametric analysis does not reveal any unexpected peculiarity, in agreement with previous analyses using different approaches. , $^{6,-8,10-12}$

- The activities decay that mainly involve the upper limbs, i.e. the throwing events (Figure 4) shows unequivocally a much more marked decline between 40 and 60 years of age, both in females and males, and reaches $50 \%$ of youth value in between 50 and 70 years. In these activities the decline of the females is initially slightly more pronounced than that of males.

Even in the only case in which gender differences in running were expected to disappear or be reversed, (i.e., in the case of very long distances, specifically longer than a marathon) the evidence is weak, if not negative. This perspective was primarily based on differences in fuel utilization, and on the analysis of marathon vs. ultramarathon performances of women and men. ${ }^{25}$ The proposed hypothesis of a metabolic advantage for women was not confirmed, possibly because the advantage of increased fat metabolism may be masked by regular feeding during endurance races. Quantitative analyses of the eventual statistically significant gender differences are above the scope of this paper and will be performed in the near future, if the described approach will be accepted by the scientific community. Based on the absence of strong evidence on mechanisms related to neuro-humoral gender differences, it could be hypothesized that the aging decline is related to some fundamental cellular mechanisms, specifically, those that control energy metabolism. ${ }^{26-31}$ Emerging are also the roles of epigenetic mechanisms, i.e., of acquired mutations in gene expression that may regulate the roles of master genes of energy metabolism. ${ }^{32-35}$ Among the main physiological determinants of endurance performance, the maximal oxygen consumption $\left(\mathrm{VO}_{2 \max }\right)$ appears to be the parameter that is most altered by age. ${ }^{24,36}$ Interestingly, the same mechanisms are present as pathogenic factors in many disorders that present behaviours described as "early or premature aging".37-39 This opens new perspectives for anti-aging countermeasures based on volitional exercise, ${ }^{12,13}$ or on other physical rehabilitation approaches. ${ }^{40-43}$ The reasons for the observed minor gender inequalities in aging decline are all to be clarified, despite an immense literature in aging gender differences ${ }^{1-4,12-14,24-28,44-46}$. It is worth noting that "The ability to maintain a high exercise-training stimulus with advancing age is emerging as the single most important means of limiting the rate of decline at least in endurance performance". ${ }^{24,44-46}$ Thus, it can be hypothesized that the observed minor gender different rates of decay are associated with biological mechanisms, but they can be equally due to socio-cultural factors, given the differences in the social life of females and males in all ages and in all cultures.
In conclusion, all together the analysis of World Records of Master athletes here described is pointing to an absence of main differences in "aging decline" of females and males. This is something fully unexpected in genderrelated sports behaviours. Implications may have longterm influences on biology, physiopathology and managements of aging per se and of its complications.

\section{List of acronyms}

CoM - Center of Mass

$\mathrm{VO}_{2 \max }-$ maximal oxygen consumption

\section{Authors contributions}

Paolo Gava played a main role in the conception, study design, and data acquisition, while Barbara Ravara participated in analyses of data and in drafting and finalizing the manuscript.

\section{Acknowledgments}

The Authors thank colleagues of the Interdepartmental Research Center of Myology, Department of Biomedical Science, University of Padova, Italy and of the A\&C MC Foundation for Translational Myology, Padova, Italy for discussions and critical readings.

\section{Funding}

The A\&C M-C Foundation for Translational Myology, Padova, Italy sponsored the publication of this manuscript.

\section{Conflict of Interest}

The authors declare they have no financial, personal, or other conflicts of interest.

\section{Ethical Publication Statement}

We confirm that we have read the Journal's position on issues involved in ethical publication and affirm that this report is consistent with those guidelines.

\section{Corresponding Author}

Barbara Ravara, Interdepartmental Research Center of Myology, Department of Biomedical Science, University of Padova, Via Ugo Bassi, 58/B 35131 Padova, Italy.

Email: barbara.ravara@unipd.it

E-mail of co-author

Paolo Gava: paologavamain@gmail.com

\section{References}

1. Barford A, Dorling D, Smith G, Shaw M. Life expectancy: women now on top everywhere. BMJ., 2006;332(7545):808.

2. Lewis DA, Kamon E, Hodgson JL. Physiological differences between genders. Implications for sports conditioning. Sports Me 1986;3:357-69. Review.

3. Hunter SK, Stevens AA. Sex differences in marathon running with advanced age: physiology or 
participation? Med Sci Sports Exerc 2013;45:14856. doi: 10.1249/MSS.0b013e31826900f6.

4. Mascherini G, Castizo-Olier J, Irurtia A, et al. Differences between the sexes in athletes' body composition and lower limb bioimpedance values. Muscles Ligaments Tendons J 2018;7:573-81. doi: 10.11138/mltj/2017.7.4.573. eCollection 2017 OctDec.

5. Gava P, Kern H, Carraro U. Age-associated power decline from running, jumping, and throwing male Masters World Records. Exp Aging Res 2015;41:115-35. 10.1080/0361073X.2015.1001648.

6. Baker AB, Tang YQ, Turner MJ. Percentage decline in masters superathlete track and field performance with aging. Exp Aging Res 2003;29:47-65. doi:10.1080/03610730390168076

7. Baker $\mathrm{AB}$, Tang YQ. Aging performance for masters records in athletics, swimming, rowing, cycling, triathlon and weightlifting. Exp Aging Res 2010;36:453-77. doi:10.1080/0361073X.2010.507433E

8. Böttiger LE. Regular decline in physical working capacity with age. Br Med J 1973:3:270-1.

9. Edmunds K, Gíslason M, Sigurðsson $\mathrm{S}$, et al. Advanced quantitative methods in correlating sarcopenic muscle degeneration with lower extremity function biometrics and comorbidities. PLoS One 2018;13:e0193241. doi: 10.1371/journal.pone.0193241.

10. Frontera W, Hughes VA, Fielding RA, et al. Aging of skeletal muscle: A 12-yr longitudinal study. J Appl Physiol 2000;88:1321-6.

11. Grassi B, Cerretelli P, Narici MV, Marconi C. Peak anaerobic power in master athletes. Eur J Appl Physiol Occup Physiol 1991;62:394-9.

12. Mitchell WK, Williams J, Atherton $\mathrm{P}$, et al. Sarcopenia, dynapenia, and the impact of advancing age on human skeletal muscle size and strength; a quantitative review. Front Physiol 2012;3:1-18. doi:10.3389/fphys.2012.00260

13. Larsson L, Degens H, Li M, et al. Sarcopenia: Aging-Related Loss of Muscle Mass and Function. Physiol Rev 2019;99:427-511. doi: 10.1152/physrev.00061.2017.

14. Metter EJ, Conwit R, Tobin J, Fozard JL. Ageassociated loss of power and strength in the upper extremities in women and men. J Gerontol A Biol Sci Med Sci 1997;52:B267-76.

15. Skelton DA, Greig CA, Davies JM, Young A. Strength, power and related functional ability of healthy people aged 65-89 years. Age Ageing, 1994;23:371-7.

16. Young BW, Starkes JL. Career-span analyses of track performance: Longitudinal data present a more optimistic view of age-related performance decline. Exp Aging Res 2005;31:69-90. doi:10.1080/ 03610730590882855
17. Runge M, Rittweger J, Russo CR, et al. Is muscle power output a key factor in the age-related decline in physical performance? A comparison of muscle cross section chair-rising test and jumping power. Clin Physiol Funct Imaging 2004;24:335-340.

18. International Association of Athletics Federation http://www.iaaf.org/

19. World Master Atheltics - http://www.worldmasters-athletics.org/

20. Samozino P, Rejc E, Di Prampero E, et al. Optimal Force-Velocity Profile in Balistic Movements Altius: Citius or Fortius? Med Sci Sports Exerc 2012;44:313-22. 10.1249/MSS.0b013e3182d757a.

21. Canavan PK, Vescovi JD. Evaluation of Power Prediction Equations: Peak Vertical Jumping Power in Women. Med Sci Sports Exerc 2004;36,9:158993. doi: 10.1249/01.MSS.0000139802.96395.AC.

22. Winter EM. Jumping: Power or Impulse? Med Sci Sports Exerc 2005;37:523. doi: 10.1249/01.MSS.0000155703.50713.26.

23. Knudson DV. Correcting the use of the term "Power" in the strength and conditioning literature. J Strength Cond Res 2009;23:1902-8

24. Lepers R, Stapley PJ. Master Athletes Are Extending the Limits of Human Endurance. Front Physiol 2016;12;7:613. doi: 10.3389/fphys.2016.00613. eCollection 2016. Review.

25. Coast JR, Blevins JS, Wilson BA. Do gender differences in running performance disappear with distance? Can J Appl Physiol 2004;29:139-145.

26. Tezze C, Romanello V, Desbats MA, et al. AgeAssociated Loss of OPA1 in Muscle Impacts Muscle Mass, Metabolic Homeostasis, Systemic Inflammation, and Epithelial Senescence. Cell Metab 2017;25:1374-89.e6. doi: 10.1016/j.cmet.2017.04.021. Epub 2017 May 25.

27. Romanello V, Scalabrin M, Albiero M, et al. Inhibition of the Fission Machinery Mitigates OPA1 Impairment in Adult Skeletal Muscles. Cells 2019 Jun 15;8(6). pii: E597. doi: 10.3390/cells8060597.

28. Favaro G, Romanello V, Varanita T, et al. DRP1mediated mitochondrial shape controls calcium homeostasis and muscle mass. Nat Commun. 2019 Jun 12;10(1):2576. doi: 10.1038/s41467-01910226-9.

29. Hood DA, Memme JM, Oliveira AN, Triolo M. Maintenance of Skeletal Muscle Mitochondria in Health, Exercise, and Aging. Annu Rev Physiol 2018;81:19-41. doi: 10.1146/annurev-physiol020518-114310.

30. Triolo M, Hood DA. Mitochondrial breakdown in skeletal muscle and the emerging role of the lysosomes. Arch Biochem Biophys 2019;661:6673. doi: 10.1016/j.abb.2018.11.004. Epub 2018 Nov 12. Review. 
31. Rodríguez-Nuevo A, Díaz-Ramos A, Noguera E, et al. Mitochondrial DNA and TLR9 drive muscle inflammation upon Opa1 deficiency. EMBO J 2018;37(10). pii: e96553. pii: e96553. doi: 10.15252/embj.201796553. Epub 2018 Apr 9.

32. Marroncelli N, Bianchi M, Bertin M, et al. HDAC4 regulates satellite cell proliferation and differentiation by targeting P21 and Sharp1 genes. Sci Rep 2018;8(1):3448. doi: 10.1038/s41598-01821835-7.

33. Pigna E, Renzini A, Greco E, et al. HDAC4 preserves skeletal muscle structure following longterm denervation by mediating distinct cellular responses. Skelet Muscle 2018;8:6. doi: 10.1186/s13395-018-0153-2.

34. Renzini A, Marroncelli N, Noviello C, et al. HDAC4 Regulates Skeletal Muscle Regeneration via Soluble Factors. Front Physiol (2018;9:1387. doi: 10.3389/fphys.2018.01387. eCollection 2018.

35. Seaborne RA, Strauss J, Cocks M, et al. Human Skeletal Muscle Possesses an Epigenetic Memory of Hypertrophy. Sci Rep 2018;8:1898. doi: 10.1038/s41598-018-20287-3.

36. Pigna E, Berardi E, Aulino P, et al. Aerobic Exercise and Pharmacological Treatments Counteract Cachexia by Modulating Autophagy in Colon Cancer. Sci Rep 2016;6:26991. doi: 10.1038/srep26991.

37. Carraro U, Kern H, Gava P, et al. Recovery from muscle weakness by exercise and FES: lessons from Masters, active or sedentary seniors and SCI patients. Aging Clin Exp Res 2017;29:579-90. doi: 10.1007/s40520-016-0619-1. Epub 2016 Sep 3. Review.

38. Carraro U, Gava K, Musumeci A, et al. Safe Antiaging Full-Body In-Bed Gym and FES for Lazy Persons: Home In-Bed Exercises for Fighting Muscle Weakness in Advanced Age. In: Masiero S, Carraro U (Eds) Rehabilitation Medicine for Elderly Patients, Springer-Nature, Cham, Switzerland, 2018, pp 43-52. ISBN 978-3-31957405-9 ISBN 978-3-319-57406-6 (eBook).
39. Hofer C, Loefler S, Kern H, et al. Two years of FES training improves muscle fibers of thigh muscles in long-term thoracic level-complete spinal cord injury. Biol Eng Med 2018;3(3):1-5. doi: 10.15761/BEM.1000S1002.

40. Kern H, Barberi L, Löfler S, et al. Electrical stimulation counteracts muscle decline in seniors. Front Aging Neurosci 2014;6:189. doi: 10.3389/fnagi.2014.00189. eCollection 2014.

41. Mosole S, Carraro U, Kern H, et al. Long-term highlevel exercise promotes muscle reinnervation with age. J Neuropathol Exp Neurol 2014;73:28494.

42. Zampieri S, Pietrangelo L, Loefler S, et al. Lifelong physical exercise delays age-associated skeletal muscle decline.J Gerontol A Biol Sci Med Sci 2015;70:163-73. doi: 10.1093/gerona/glu006.

43. Zampieri S, Mammucari C, Romanello V, et al. Physical exercise in aging human skeletal muscle increases mitochondrial calcium uniporter expression levels and affects mitochondria dynamics. Physiol Rep 2016;4(24). pii: e13005. doi: 10.14814/phy2.13005. Erratum in: Physiol Rep. 2017 Mar;5(6).

44. Tanaka H, Seals DR. Endurance exercise performance in masters athletes: Age-associated change and underlying physiological mechanisms. J Physiol 2008;586,55-63. doi:10.1113/jphysiol. 2007.141879.

45. Tanaka H, DeSouza, CA, Jones PP, et al. Greater rate of decline in maximal aerobic capacity with age in physically active vs. sedentary healthy women. J Appl Physiol (1985) 1997;83:1947-53.

46. Wiswell RA, Hawkins SA, Jaque SV. Relationship between physiological loss, performance decrement, and age in master athletes. J Gerontol A Biol Sci Med Sci 2001;56:M618-26.

Submissions: June, 03, 2019

Revision received: June 17, 2019

Acceptance: June 19, 2019 